\title{
Linguistic choices and transcultural identity construction in Mary Specht's Migratory animals ${ }^{1}$
}

\author{
Romanus Aboh \\ Lecturer \\ Department of English \\ University of Uyo, Nigeria \\ E-mail: romanusaboh@uniuyo.edu.ng; romeaboh@gmail.com
}

Submitted: October 3, 2017/ Accepted: April 29, 2018 / Published: June 8, 2018

\begin{abstract}
The study of literary texts within their contexts of production has been the primary concern of literary discourse analysts. Against this backdrop, this paper examines the confluence between Mary Helen Specht's use of language in her novel, Migratory animals, and the articulation of transcultural identity. The preference for Migratory animals over other novels is motivated by the fact that the novel provides evidence of how people live in transculturalism. The analysis is anchored on literary discourse analysis, an aspect of discourse analysis that deals with the social context that backgrounds the production of literary texts. The paper reveals that though an American, Specht deploys Nigerian expressions, loanwords from Nigerian languages and Nigerian Pidgin expressions to situate her novel in the context of transculturalism. Also, the analysis suggests that the way people use language in socio-discursive situations can enrich our understanding of the identities they create either for themselves or for others.
\end{abstract}

Keywords: transculturalism, loaning, Nigerian English expressions, Nigerian Pidgin English, Migratory animals

${ }^{1}$ The author is grateful to the African Humanities Program (AHP) of American Council of Learned Societies (ACLS) for supporting this study by giving him the opportunity to attend the Manuscript Development Workshop for Journal Article Writing at Kampala, Uganda in 2016. He also acknowledges the contributions of the participants (fellows and mentors) whose suggestions helped in reworking the manuscript. Also, the three anonymous reviewers are appreciated for their close reading of this paper. 


\section{Introduction}

The aim of this paper is to illustrate how Mary Helen Specht's Migratory animals shows a symbolic parallel between the use of language and transcultural identity construction. Specht, an American novelist who was a Fulbright fellow at the University of Ibadan between 2006 and 2007, returned to America in 2007 to produce her debut novel, Migratory animals in 2015. The novel describes the world as a cornucopia of people living in transculturation. Through the metaphor of birds or travel imagery, the novel depicts people's cultural migration from one part of the world to another. Specht's character formulation of Kunle, Santiago, Flannery, Alyce, Molly, Brandon, Steven and Harry shows Specht's firm disposition to transcultural identities. These are characters who have, at various points in their lives, moved around the world such that their behaviour points to them being a combination of several cultures. For example, Santiago is Hispanic-American who has travelled to different parts of the world. However, the emphasis in this paper is on the migration from America to Nigeria, focusing on Specht's narrator and heroine, Flannery. It is through her that we come to terms with the polygonal feature of other characters.

Specht's novel illustrates the shifting trend of literature in terms of focus and linguistic resourcefulness. The novel brings together opposing cultural forms, transcends differences and generates an 'other space' where Specht's articulates her desire for cultural pluralism. In Migratory animals, therefore, the reader comes across issues that are germane to transculturalism -family bonding, illustration of the positive effect of transnationalism and migration, home, cultural hybridity, mixed identities, broken relationships and unfulfilled dreams. These issues imprint transculturation on the text and its form, illuminating the connection between the intended message and the central metaphor of the novel, migratory birds. Flannery is presented as the prototype of her generation because she offers a reflection of a moral code arising out of a combination of innocence, love, alienation and redemption. Kehinde argues that both 'contemporary American and African writers prioritise cultural 
pluralism to envision enduring experience and consciousness of mixed racial, ethnic and cultural identity' (2010, p. 231). The author of Migratory animals appears to be interested in depicting the significance of contemporary existence, global interaction and the migration not only of individuals, but of cultures and identities across the globe.

Migratory animals captures the notions of identity and transculturalism in that the novel traces the coming of Flannery, a young scientist, to Nigeria, her romantic relationship with Kunle -a postgraduate student at the University of Ibadan and the complex turn of events. Drawing from the subjects of migration, transnationalism and transculturalism, Specht depicts the fragmented nature of human existence. The novelist presents us with a panorama of American and Nigerian life where her characters engage questions of culture, identities and belonging. This trajectory is profoundly exemplified in the character of Flannery. Flannery, whose characterisation schema details the modern individual's multi-layered existence, breaks the kernels of her American-ness to take up a Nigerian identity or something akin to it. Essentially, Flannery's duality as expressed in 'migration' dramatises a motivation to locate one's self in a continuously mutating world.

Although there are instances where other languages, most frequently Spanish expressions (No mames, giiey and Callate, gringo p. 201), for example, are used in the novel to depict transculturalism, our concern in this paper is to interrogate how Nigerian ways of using English echo transcultural identity construction in Migratory animals. The author, in her creative inventiveness, interlaces her narrative with her experiences in Nigeria and it is in this kind of interspacing that the collective narrative of the novel takes shape and its central metaphor of migratory animals finds articulation in our fragmented reality. Through Flannery, also known as Flan, Specht delineates what is Nigerian as well as allows Flan to take up a voluntary identity. Voluntary identity, as conceived by Kavalski, 
depicts the idea of an independent choice of individual identity accentuated by a more flexible understanding of cultural frontiers; it is an articulation of the conjecture of the past with the social, cultural and economic relations of the present. (2003, p. 3)

Specht's description of Nigeria's culture through the prism of Flannery's characterisation is an instantiation of the multidimensionality of humankind. This is why Flannery does not consider it an issue to be 'Nigerian'. Her willingness to marry Kunle and ability to find Nigeria habitable implies that Nigeria is her constructed new home. She admits: 'it really hadn't been difficult to adjust to daily life in Nigeria' (p. 137). But Specht's construction of dual identity relies on her ability to use American English, Nigerian English, Pidgin and indigenous expressions. It could be said that her understanding of the culture of the Nigerian people helps in making her creative process an effective link between literature and reallife situations. Bitsani elucidates this process when she postulates better that 'cultures and identities are dynamic sets, they change over time and adapt to circumstances. They are also complex wholes, encompassing heterogeneous components' (2016, p.3). It is, therefore, difficult to 'coagulate' or abridge them at just one level. Bitsani's observation has epistemological validation since one can hardly talk about an entirely pure or singular culture. To study language in terms of identity construction implies buttressing the fact that cultural identity is a constantly shifting phenomenon because neither identity nor language is fixed. The changes we see in language are but a reflection of the changes that take place in human lives and people's ways of perceiving the world. It is in line with the above that this paper examines Specht's use of loaning, Nigerian English expressions and Nigerian Pidgin, exemplifying how her linguistic choices shed light on people's transcultural identities in the fictional world of her novel and in the wider referential world that frames the narrative. 


\section{Transculturalism}

Definitions of transculturalism, like identity, are varied and rooted in different scholarly traditions or orientations. Transculturalism, according to Onghena (2008, p. 183), is 'a process the elements of which are altered and from which a new, composite and complex reality emerges; a reality that is no mechanical mixture of characters, nor mosaic, but instead a new, original phenomenon'. Transculturalism, therefore, describes a practice in which the singularity of existence is altered, thereby creating opportunities for the emergence of a complex reality. Kehinde defines transculturalism as 'a quintessential weapon for uniting peoples across races, ethnicities and cultural divides' (2010, p. 231). Kehinde's argument underscores the fact that transculturalism, in practice, breaks individual, cultural and national limitations. People or nationals no longer live in a single culture; they embrace multiple ways of configuring the world.

In a similar vein, Tartaglia contends that 'transculturalism is about looking for shared interests and beliefs, which cut across cultural, historically contingent boundaries' (2016, p. 1). This postmodern trait is a further illumination of coming together of cultures because there is hardly any society in today's world that is insulated from the others. The advancement in technology, for example, is making it easier for people across diverse cultural spaces, races and nations to share their ways of life with others as well as appreciate other ways of doing things. In so doing, the world is being brought together and the individual becomes a compendium of manifold identities. Perhaps another way to say this is that transculturalism tries to explain that cultures are being fashioned, shaped and influenced by their constant interactions. Culture and identity are not static, and are in a constant state of flux, making every individual a mosaic of cultural identities.

In the context of transcultural identity construction, linguistic identities describe 'the sense of belonging to a community as mediated through the symbolic resource of language, or to the varying ways in which we come to understand our language 
ourselves' (Park, 2012, p. 1080). Through the linguistic choices we make, we position ourselves in a social context. Linguistic identities become, in the context of transculturalism, central to our understanding of the world because 'most of people, ideas, products, and cultural forms across national boundaries intensify contact among languages' (Park 2012, p. 1080). This suggests a symbolic parallel between meaning-making and context of discourse.

Identity construction, therefore, is a constitutive part of human existence and can manifest in different forms and various human transactions. However, the notion has remained very difficult to define. It could be seen as the way an individual wants to be regarded or the way an individual is regarded or constructed by others. The multifaceted and fluid nature of identity is perhaps the reason why Ahmed (2016, p. 138) argues that 'identity can, hence, change, just like the chameleon's multicolours, to suit different situations and occasions'. Ahmed's position resonates with the concept of transcultural identity. Human experience and existence, argues Cuccioletta, are 'due to the contact with the other, who in reality is like, oneself' (2002, p. 2001). Although there are factors that articulate as well as construct people's identity or identities, language is central to identity enactment. One's knowledge and use of language reveal much about one's experiences in life, the reason this paper focuses on Specht's use of language.

\section{Theoretical framework}

This paper is anchored on the analytical principles of literary discourse analysis (LDA). The development of LDA as a branch of discourse analysis in the 90 s produced a profound transformation in the condition under which literature can be studied (Maingueneau, 2010). As an approach of analysing literary texts from a discourse analysis perspective, unlike traditional stylistics, LDA deals with literary texts 'as part of the discursive practices of a given society' (Maingueneau, 2010, p. 152). Thus, LDA is concerned with the function language performs in a particular context. It deals with 'the specific use of language in literature' (van Dijk, 1985, p. 1), focusing on how sociocultural context intersects with meaning- 
making as well as explication. Expressed in another way, LDA is interested in reviewing and explaining the origin and the nature of the social meaning attached to both the linguistic and literary forms.

Proponents of LDA -Tolliver (1990), Vendonk, (2002), Porras, (2011), among others- strongly hold the view that the complete meaning of discourse can be understood from the context rather than the sentence. Therefore, understating context will make 'reading a purely relativist process' (Miall, 2002, p. 324) and also what the text is saying will be forcefully foreclosed. 'Literary interpretation', argue Allington and Swann, 'is wholly contingent upon socio-interactional context of a particular reading event or activity, and the most interesting aspect for analysis is the way these socio-interactional contexts (involving individual and group identities, for instance) are produced and reflected in the discourse' (2009, p. 227). The context in which a text is situated is very important to LDA.

Context, in LDA, describes the situations in which something exists (Yina, 2011). A reader of a text is therefore required to have profound understanding of the sociocultural context of the text's discourse in order to account for what a text is actually saying. Yina further argues that the conception of 'literature as discourse allows the reader to create his own contexts of meaning adduced in actual manifestation of behaviour and attitudes depicted in a text' (2011, p. 19). As a literary representation of reality, literature as discourse 'enables us to account for the artistic axiom that different readers in different times and places would attach different sets of contextual interpretations to one and the same verbal structure or text' (Yina, 2011, p. 20). LDA locates the language of literary texts within its context of production. The ideas that inform the writers' use of language are important indices to be considered by analysts in order to understand the fundamental message of a text. Both the text and the context of the text are important to the literary discourse analysts. Maingueneau reasons that 'for discourse analysts, there is no inside and outside text. What is "inside" must construct its own "interiority" through interdiscourse' (2010, p. 151). Therefore, 
it is less helpful to analyse Specht's Migratory animals without recourse to the Nigerian sociolinguistic milieu in which the novel is partly situated.

In conjunction with the above, Bradford (1997, p. 96-97) argues that 'Language is always dependent upon its historical contexts. The conventions of speaking and writing reflect or engage with the social, political or ideological resources of a word, a phrase or locutionary habit, and these non-literary registers inform the texture of poems and novels'. It follows that, in order to understand how transcultural identity is constructed, one needs to understand how language works in context-specific ways. This analytic paradigm has more sociocultural direction since the analysis of texts, in terms of meaning-making, involves the analysis of broader, fundamental discursive questions. Meaning is not semantically fixed; therefore, meaning-making crucially 'depends on the essential indeterminacy of language' (Widdowson, 2012, p. 15). Literary discourse analysts, then, are interested in deciphering the various hidden significations of a text. They project the idea that the analyst should be interested in analysing the web-like trajectories of linguistic choices, identities and cultural ways of speaking. Widdowson makes the point that understanding literary texts 'is particularly elusive', because 'literary texts do not key into context and pretext in conventional ways' (2012, p. 5). Deducible from the foregoing argument is that LDA supports variable ways of reading texts in order to highlight how discursive encounters confluence with the meaning-making process. Therefore, LDA accounts for how social, psychological and socio-historical contexts influence the art of communication.

The way people use and interpret language is often linked with their identities. In line with LDA's analytic principle of engaging literary texts from contextual perspectives, Specht's Migratory animals can be seen as an authentic sociocultural linguistic corpus. Ajtony (2013, p. 258) explains that 'The social variables that shape identity of the characters are tied to their language use and social behaviour'. The concern of this study, then, is to investigate the role language plays in literary characters' articulation of their 
multifaceted existence.

\section{The use of loanwords in Migratory animals}

Loanwords are not the only linguistic means by which transcultural identity is enunciated. But loanwords have underlying meanings; they transcend stylistic motivation to provide information about why people use language the way they do. Loaning and borrowing are two code-switching phenomena that have been used interchangeably without paying close attention to the sharp peculiarity that exists between them. Code-switching, a common feature of bilinguals/multilinguals, describes the simultaneous use of two or more languages in written and spoken situations (Lamidi, 2017). While a loanword, as described by The Oxford companion to the English language, refers to 'a word taken into one language from another' (1992, p. 623), borrowing goes far past taking an individual word to show the structural changes the borrowed words undergo as they leave one language to a host language. Loanwords deal with individual words; 'lexical borrowing implies the adoption of individual words or even large sets of vocabulary items from another language or dialect' (Aboh, 2012, p. 53). The difference between the two linguistic notions is that the former is about single words, also known as 'switch tag', while the later involves 'large sets of vocabulary items' (Rahim, 2008, p. 5).

Although there are many languages (Spanish, Yoruba, Nigerian English, Hausa, etc.) that used in the narrative, the focus of this paper is on loaning from Nigerian languages to English. As writers loan from one language to another, they provide information about their 'double' or 'multiple' selves. Specht deploys loaning as a narrative strategy to reflect the transcultural composition of her major character, Flannery. For example, there is the use of Oyinbo. In Nigeria, anyone who is white in complexion is called an Oyinbo. Kunle, as well as other Nigerians, calls Flannery, the white American, Oyinbo. When she returns to America, she tells Molly, her sister, what the lexical unit means. By so doing, Flannery imprints in Molly's consciousness that if she has the opportunity to be in Nigeria, she will also be called an Oyinbo. But perhaps 
the most significant aspect of such a linguistic socialisation is that the lexical unit reveals how Flannery has learned a new word, a word that defines many Nigerians' naming technique, especially in western Nigeria - because the word has a Yoruba etymology. In learning a new word, she also learns another way of understanding the world. This makes it possible for us to talk of both identities and transculturalism.

In her 'new world,' Flannery does not quite encounter difficulties in adapting to Nigeria's lifestyle. Her transmutation appears to be very fast. For example, she and Kunle go out to drink palm wine, juice tapped from palm trees in most parts of Nigeria, and as they drink from little plastic cups, 'Flannery imagined she and Kunle were bound in the pages of The palm-wine drinkard [an allusion to Amos Tutuola's novel] [Has been included in the References] and sitting and drinking was the only job they had in the world' (p. 4). Specht, in this instance of language use, forays into a cultural pattern of her host community where members of the community sit out to drink palm wine and have open conversations about what their immediate environment offers. But more than this, palm wine functions as a means of formulating a Nigerian identity for the American. The palm wine drinking is one spectacular moment for Flannery as it captures a series of symbolic identity constructions for her, which draws strongly from the overall metadiscursive context of transculturalism. It is not that she attempts to forget or obliterate her American identity; rather, she provides a compelling example of how human beings navigate the seams of cultures and identities. It is this intersection of multidimensionality that Hobsbawm clarifies:

The concept of a single, exclusive, and unchanging ethnic or cultural or other identity is a dangerous piece of brainwashing. Human mental identities are not like shoes, of which we can only wear one pair at a time. We are all multi-dimensional beings. (1996, p. 1067) 
Hobsbawm persuasively argues that individuals operate a framework of multiple identities. Even nations that are thought to be homogenous are, in effect, heterogeneous in identity. For, there are diverse people, in that supposedly homogenous nation, with diverse ways of existence, of viewing the world. Flannery goes on with her daily life the way she finds Nigerians do.

Language constructs identities and gives us belonging. Kunle uses abi? (p. 15), a Yoruba expression that translates roughly as 'isn't it?' or 'right?', when talking on the phone with Molly. In non-literary situations in Nigeria, interlocutors loan the word as a conversational strategy to 'make' listeners agree or confirm what they say. The fact that Kunle uses the Yoruba word with an American who has never been to Nigeria should not be conceived as a demonstration of arrogance but a deliberate act of identity 'transfer'. He presupposes that Molly would understand what it means. But most importantly, in 'fixing' this word in her characters' mouth, Specht typifies the fact that one does not necessarily have to live in a particular community for one to imbibe the cultural patterns of a people, for language embodies the ways of life of a people. Kunle's use of abi while talking with Molly is strategic in that he has expanded the linguistic frontiers of English so as to relate in an unencumbered manner with Molly.

There is the calculated loaning of wahala by Flannery when she thinks of Molly. Wahala is a Hausa expression that translates as 'trouble', 'problem' or 'controversy'. But the context actually determines the depth of the meaning. In some cases, its meaning is weightier than mere 'trouble' or 'problem'. Having lived in Nigeria, Flannery understands that it can be used to mean more than 'trouble'. This is the reason she loans wahala to tell the degree of the psychological trauma Molly is undergoing because of Huntington disease - a genetic disease passed to her from their mother. In displaying transculturalism, Flannery, through the discourse strategy of linguistic apposition, tells us what wahala means - 'big trouble' (p. 16). Wahala better explains what she thinks of Molly's situation. It is fascinating to see how Flannery navigates the seams of existence through the linguistic choices she 
makes.

Specht loans indigenous expressions in her creative initiative to explain the conflation of language and the presentation of sociocultural reality. She uses the Nigerian term Okada which describes both a commercial motorbike and the rider. Ontologically, it describes a town in present-day Edo State, Nigeria. Flannery systematically mediates an internal sense of belonging to Nigeria. This feeds into the fact that she will become Nigerian if she marries Kunle. Kunle is a Yoruba-Nigerian Flannery falls in love with. She reminisces about the way

they sped by on the back of an Okada. ... Flan behind the driver; Kunle behind her. She remembered how his breath passed along her ear and the side of her face as she leaned back into him. His legs straddled hers, and his hands barely touched her torso as if held there not by muscle but by magnetism. It was joy and movement and freedom in a liminal space, invisible ghost licking at their heels. (p. 22)

Although there are motorbikes all over the world used both as private and commercial means of transportation, the lexical entity Okada is a means of transportation that is specifically known by Nigerians. The word 'movement,' in the context of the novel, is symbolic: it connotes a transitional process Flannery undergoes to embrace a new identity while maintaining her American-ness. In this instance, it does not seem out of place to argue that Okada systematically functions as a vehicle of psychological identification: a means that liberates her from cultural constraints. Specht's use of language activates Flannery's schema of dual or multiple existences. The preference for the Nigerian expression over the English one (motor bike) should not be read as Flannery's eradication of her Americanness, but an explicit account of her 'transcultured selves'. This is why when she goes back to America, she feels a deep sense of incompleteness without Kunle and she laments: 'I wish Kunle were 
here' (p. 41).

Relatedly, there is the loaning of danfo (p. 41), a minibus taxi. Although the origin of the word danfo is not certain, it means 'hurry' in Yoruba. It is one of the chief means of commercial transportation in Lagos, Nigeria. A ride in a danfo can be quite uncomfortable; it is not the best means of transportation because of what it signifies. Significantly, the novelist deploys danfo to provide her readers with visual accounts of transportation system in the city of Lagos. So Flannery imagines when Kunle 'would be riding a Danfo crowding four to a seat...painted with maxims like "Protected by the Blood" or "No food for lazy man" (p. 41). The other important thing to note from the above use of language is Flannery's consistent psychological flux between America and Nigeria that represents a further illustration of transculturalism. Besides that, expressions such as 'Protected by the Blood' and 'No food for lazy man' are hand-written inscriptions one finds on commercial vehicles and on some private cars in Nigeria. They function as semiotic constructs because they enable Flannery to identify with and accept something new, something that, perhaps, she does not see in America. Both Okada and danfo function as transforming processes that diminish the concept of a single identity.

In her cultural excursion into Nigeria's ways of life in terms of greeting, Flannery loans the Yoruba word ekaaro (p. 135) to illuminate the premium some Nigerians place on greeting. It means 'good morning'. Unlike the American greeting culture, ekaaro comes with body movement -the male child is expected to prostrate and the female to genuflect while greeting an elderly person. This body movement speaks volumes for the amount of respect attached to greetings in Nigeria, implying that it goes beyond phatic communication. Meeting with Kunle's mother, Flannery takes on a different identity than the American one. She switches from the formal mode of the English language to Yoruba which carries its own sensibilities and social functions. Hudson argues that 'the choice of language at a point is decided by situation which in turn is defined by it' (1996, p. 53). Hence, Flannery having understood that she is conversing with a Yoruba woman, uses the expression 
ekaaro. Flannery's conscious cultural transportation intersects with her identity construction goal. This is manifest in her tongue swap. Her linguistic representation echoes Onghena's (2008, p. 182) view, 'we can safely say that cultures are constantly evolving and that we should consider them dynamic. Moving from the descriptive to the more explanatory nature'. It does not appear to be out of place to mention that Flannery's loaning indicates her transitive process of navigating two cultures simultaneously.

The position of this paper is that there seems to be a conjunction between the language of literature and the identity that produced it. The deployment of suya (p. 154) to capture the culinary habit of many Nigerians is an instantiation of the foregoing conjecture. Suya describes strips of beef with oil sprinkles grilled on skewers over open fire. It is a Hausa expression that is commonly used in Nigeria. Knowing this, Flannery buys it for Kunle and they both sit out 'devouring' it (p. 154). While Flannery is familiar with grilled meat, it can hardly be said that she is used to suya. Even Kunle marvels at Flannery's adaptability. He says, 'I'm surprised an oyinbo can take the spice'. Therefore, her having suya despite the fact that it is spicy could be seen as an attempt to calibrate herself into the cultural pattern of Nigerians in terms of food. This is why Ajtony argues that 'the social variables that shape the identity of the characters are related to their language use and social behaviour' (2013, p. 258). It is during the scene of suya eating that 'they talked about their childhood'. The 'suya atmosphere' offers a perfect opportunity for them to dig into their respective histories, enabling them to get to know each other even better. This is a dynamic transformation, an indexicalisation of our polygonal existence. The next section of the paper focuses on the significance of Nigerian English expressions in Migratory animals.

\section{Nigerian English (NE) expressions}

Extensive studies by Odumuh (1984), Jowitt (1991), Adegbija (1998), Udofot (2007), Aboh and Uduk (2016), among many others have validated the existence of a variety of World Englishes known as Nigerian English (NE). These scholars, in 
their respective studies, have described the dynamic use of English in Nigeria as domestication, nativisation, acculturation and hybridisation. As in a typical Nigerian novel, there are numerous uses of Nigerian English expressions such as goat stew, pepper soup, Calabar stew and periwinkle snails in Migratory animals.

Pepper soup is a special type of pepper-based consommé made with meat or fish, and prepared mostly without red oil. While most Nigerians prepare and enjoy pepper soup at home, it is worth noting that it is also served at restaurants. As the name suggests, it is usually very peppery. Goat stew (p.135) is prepared with mutton or the offal of a goat. Calabar stew (p.136) is a kind of Efik soup known as edikang ikong and is consumed in many parts of Nigeria, especially the south. Periwinkle snails (p.136) are obtained from some Nigerian rivers and are used to make soup and other sorts of food. By making specific references to Nigeria's food technology, Specht takes her readers on an anthropological excursion into the culinary culture of Nigerians. As she does so, she allows Flannery to manifest her transcultural identity. Food is a constitutive aspect of a people's material culture. The various references to Nigeria's food culture in Migratory animals transform the author's natural setting, enabling her to enact not only a Nigerian identity for her characters, but to also draw attention to people's fragmented existence. Apart from Flannery, characters such as Santiago, Brandon and Alyce are typical manifestations of our split existence.

Using language as the gateway to Nigeria's linguistic space, Specht reproduces a pattern of life that is ontologically Nigerian. For example, the expression Calabar stew, as used when

One of Kunle's neighbors from Cross River State stuck her head in to ask if they'd eaten - "Done chop?" They spooned up her Calabar stew, sucking the periwinkle snails from the shells and scooping big chunks of leafy greens with balls of soft fufu made from boiled cassava. (pp. 136137) 
The passage provides cultural information about the food culture of the Efik ethnic group of southern Cross River State in Nigeria. The sucking of periwinkle snails and swallowing of balls of fufu are telling examples of the eating pattern of the people described. The fact that Specht's central character finds herself assimilating such a pattern of life is an illumination of her multiple existences. Specht tells of how 'Flannery was living in mental possession of two worlds' (p. 224).

In a similar anthropological cum historical excursion, the expression, Boys Quarters (BQ), refers to the quarters where (male) servants are housed. Boys Quarters is a vestige of colonialism that has continued to recur in NE usage. In Nigeria today, as in some ex-British colonies such as Sierra Leone, The Gambia and Uganda, some people build a main house and a special, small apartment slightly cut off from the main residence and they call it $B Q$, a place reserved for the 'boys' and possibly home helps. In other instances, it is reserved for non-members of the immediate family and visitors. Many present-day Nigerian $B Q s$ do not have that subservient, dehumanising colonial tinge. Flannery tells us what a $B Q$ means:

Kunle's room was in a BQ, or 'Boys Quarters,' a term for the small building adjacent to a residence that, during colonial times, had been used to house servants or 'houseboys.' BQs - and his was no different - were usually a row of three or four rooms connected by a slab porch, which, since there wasn't a proper kitchen, was where inhabitants set up hot plates and buckets of water. (p. 135)

Besides providing architectural information about BQs and the fact that it is a colonial vestige, it tells us about some students' housing lifestyle in some Nigerian universities, specifically the University of Ibadan. When Flannery goes to see Kunle, she is amazed how he lives in a small apartment with two other postgraduate students. Whenever $B Q$ is mentioned, many Nigerians can tell what it means 
because it describes a familiar housing system. Significantly, Specht has consciously unravelled the historical situation and condition responsible for the creation of a linguistic expression that can be deemed as typically Nigerian and West African. As much as Flannery does not belittle where Kunle lives, she identifies with him: such identification is significant in the understanding of transculturalism. Kalpana corroborates this, as he notes, 'identity is stuck within the nation's history, for individuals are at a point identified only if they have a location within the historical moment' $(2015$, p. 50). We can then say that Specht's use of language symptomises how writers use their artworks to give expressive force to transnational identity.

According to the backdrop provided by Specht's narrative, it could be argued that Migratory animals is anthropological in many ways because it insightfully details Nigeria's culture. The Nigerian identity reproduced throughout the novel provides an objective ground for a valid discussion of transcultural identity construction. The expression, village, in Nigeria describes a rural, undeveloped area as contrasted with an urban area so that my village means my rural, undeveloped hometown where my roots lie. An important indicator of the use of my village is that it connects a Nigerian to his or her roots. It has everything to do with identity and one's place of birth. There is a saying in Nigeria that 'everybody comes from a village', meaning that, however sophisticated or educated one may be at present, one's roots are located in an underdeveloped place called village. It is in my village that kerosene lamp (a local lamp made with a reduced metal can with a wick in the middle that uses kerosene to burn) is used by villagers. Specht succinctly details village life in:

Kunle's village was beautiful in its way - a pastoral answer to the maddening crowds and jammed roads of the major Nigerian cities. Women carried water on their heads, to and fro from the wells. Cocks fought and chased each other while the occasional teenager kicked up dust on a motorbike, probably going nowhere, 
killing time. (p. 159)

For the Nigerian who has lived or been to the village, these are familiar features of rustic glamour: pastoral décor and answers, women (not men) carrying water on their heads, cocks fighting and chasing each other. True to Specht's narrative, it is in the village that Kunle's mother uses a kerosene lamp to illuminate the kitchen and the compound. It is also in the village that mango trees are commonly found. Each of these expressions represents life in many Nigerian villages. It is not that village is a Nigerian English word, but its deployment in the novel reflects a typical Nigerian rustic lifestyle, which Flannery comes to like. For Flannery to consider Kunle's village beautiful and habitable in its pastoral way means that she has accepted where he comes from, and to accept his origin is to accept him for who he is. This has a mental representation that people shift in tune with the shifting nature of reality to have a new definition.

The expression let me land is an example of semantic shift in NE. It means allow me to make my point or let me be through. In either Standard British or American English, to land is to bring an aircraft down onto solid ground or water, especially in an airport. Contextually, Kunle reads through Flannery's data and becomes unhappy because she is elongating her stay in America only for a 'mere' cloud seeding. On interrupting him when he finally makes up his mind to discuss her overstay, he says, 'let me land' (p. 195). Immediately, Flannery gives him back his conversational turn. Flannery understands what Kunle means because she has lived in Nigeria and knows what Nigerians mean when they say 'let me land'. This, of course, is an explication of linguistic transnationalism. The fact is that Specht's use of language demonstrates the way many Nigerians use English. The Nigerian English expression is often used when a speaker's conversational turn is interrupted. In line with this analytical approach, it can be argued that Specht's Migratory animals is a linguistic behaviour that highlights the role of language in displaying our transcultural identity. 
Nigerian speakers of English demonstrate a penchant for creative usages that often link the created expressions with their context of use. In Nigeria, according to Eka (2002, p. 80), the Nigerian English expression been-to(s) describes 'someone who has travelled overseas, particularly to Britain'. Eka further explains that the term has a social meaning in that it tells of Nigerians who were early visitors to Britain. And when they returned to Nigeria, they were in the habit of announcing it to people that they had been overseas, had 'been to' Britain, for example. So, the word was seen as an appropriate tag for such people. Specht uses the expression in a similar way. She tells us that been-tos are "people who had been abroad' (p. 192). Such a usage signposts the mutual influence that English and Nigerian languages have on each other in the Nigerian sociolinguistic context, thus testifying to the healthy co-existence between the languages in this contact situation. It also confirms that in transculturalism, as languages come in contact with each other, they also exchange cultural ideas. Against this context, this paper insists that Specht's linguistic choices illuminate her thematic thrust in Migratory animals. Having drawn attention to the use of some Nigerian English expressions in the construction of transcultural identity, the attention of the paper will be turned to the deployment of Nigerian Pidgin expressions in relation to the enunciation of transcultural identity.

\section{Nigerian Pidgin in Migratory animals}

Nigerian Pidgin (henceforth NP) is English-based; it draws from the vocabulary of the English language and from indigenous languages to form a new unique language. Balogun draws attention to the fact that 'The dynamic and generative capacities of Nigerian Pidgin to create from a finite set of lexical items have continued to foster communicative process and interaction among Nigerians' (2013, p. 90). However, NP is mostly used in informal transactions. It is a vehicle for the formulation of friendly relationships among its users. Some NP expressions used in Migratory animals are examined presently. 
Aboh, R./ Linguistic choices and transcultural identity construction

The expression Body no be firewood has several significations. Specht narrates Flan's thoughts:

There was a saying in Nigerian pidgin: "Body no be firewood," meaning that a body is not meant to be put through all the searing pains and horrors of this life. But when she'd first heard Kunle use the phrase, she thought he was talking about romantic sparks, the burn of physical attraction. Love turning your body into sticks of firewood. (p. 42)

The context in which the expression, Body no be firewood, (literally means 'the body is not a log of wood') is used determines its meaning. It can be used by someone who has been stressed or strained to mean that his/her body, unlike firewood, is not meant to be subjected to unbearable suffering. But it is also commonly used in Nigeria to refer to sexual craving or readiness, suggesting that one is not as sexually insensitive as a log of wood. Flannery thought that Kunle, using such an expression, means his sparkling love - as firewood does when burning - towards her, but later she realises that his usage aligns with the explanation offered above. She understands this more in the stressful situation she finds herself in.

One noticeable feature of NP is that it is 'liberal' and fluid. Sometimes, its meaning can be deduced from its subtle, witty and metaphorical combination of individual words. This can be seen in the interaction between Flannery and Kunle:

'I'm sorry I'm not in a better state. It's not often

I get house calls from Americans. How do you find Nigeria?' This was a question everyone asked Flannery and two other Americans working with her.

'I like it here. I'm still here'.

'You try small, small. But for how much longer'? he asked. (p. 136) 
The expression, You try small, small, has its cultural embedding: the reduplication, small, small, is used to commend someone who has been able to perform a given task to an extent so that small, small means that the commendation is commensurate with the impartial completion of a duty. In the case of Kunle and Flannery, the remark is on her commendable progress, encouraging her to do more. She is commended for her first-time experience in Nigeria as she tries to adapt to it. The language - NP- that is used is not a language Flannery has originally known. But the time she has spent in Nigeria enables her to understand what Kunle means. A symbolic aspect of Kunle's use of language is his intention to 'initiate' Flannery into Nigerian ways of using language.

One inference that can be drawn from Specht's novel is her reflection of Nigeria's cultural semantics. Since many Nigerians still live communally, a member of a community would always want to know how other members of the household or community are faring. There are questions asked about one another's welfare, health status and, in fact, well-being in general. These cultural tenets are backgrounded in NP expressions such as Done chop? (p. 136), How body? (p. 138) and Body fine-o (p. 138). In a sense, while Done chop? is a question that ordinarily asks whether one has eaten or not, it implies more. It usually comes from a caring friend or relative. Specht tells us how, 'One of Kunle's neighbors from Cross River State stuck her head in to ask if they'd eaten - "Done chop?"' (p. 136). The question, Done chop? ('Have you eaten?'), demonstrates the communal practice of Nigerians as well as details the charitable things Nigerians do for one another. It presupposes that despite the fact that most Nigerians' modes of living bear marks of western influence, some communal fragments are still noticeable among contemporary Nigerians as can be inferred from the use of NP. Specht portrays the life of living together and sharing possessions and responsibilities as a feature of transculturalism. Corroborating this postulate, Amao contends that 'Nigerian pidgin is also acknowledged as a formidable stride in the re-creation of Nigerian and African socio-cultural identity' (2012, p. 45). Specht tells us that Flannery not only observes this cultural exigency, but 
participates fully in the process.

Through the use of this pidgin expression, we can understand a connection between food behaviour and the formulation of a new identity. Perhaps we should not forget that Flannery does not at any time reject any Nigerian food she is offered. Kunle tells his aunt, 'Flan loves our food' (p. 223). It is in the eating of the food that she actually comes to know their names. In this way, we understand the efforts she makes to forge a new identity for herself, a formulation that does not destroy her American-ness. Rather, it is an identity that makes her fit snugly into the complex dynamics of human manysided existence. Accordingly, although food in principle is morally neutral, in practice, it makes moral and political statements. It is a site, in fact, an advantaged site for the enunciation of identities. Even when Kunle's pronominal choice -our- appears to exclude Flannery, it captures his desire to see Flannery as a member of his group. In this way, 'our' rather expands to include the American.

Similarly, How body? with its corresponding response Body fine-o is a question that requests an answer not just on the respondent's physiological well-being (as could be inferred from the linguistic context of the sentence) but also on his/her total wellbeing, which includes psychological, social, economic, financial, mental health and, in fact, family relationship. In this sense, the answer Body fine-o could be synonymous with the English version of All is well. Some NP expressions are pure transliterations of indigenous languages. In the novel, the very first words Kunle used when Flannery calls him on the phone are How body? and she responds Body fine-o. From this question-response transaction, Kunle is certain that, all things being equal, Flannery is doing well back in America.

Every point at which Specht deploys a Nigerian Pidgin expression seems significant to our understanding of the discourse of transcultural identity construction. Kunle's village is a stark contrast to the noisy, busy and crowded Nigerian cities. Back home in Kunle's village, Flannery will always notice Kunle's mother shake her head signaling her disapproval of Flannery's consistent going out. The likes of Flannery, according to Kunle's mother, are 
called waka waka. The term could be either derogatory or jocular. It is derogatory when used to describe a commercial sex worker, and jocular when used to refer to one who likes going out a lot. The latter meaning explains why Kunle's mother calls Flannery waka waka (p. 159). Thus, waka means 'to walk' and 'waka waka' means 'to walk a lot'. The meaning of NP words and expressions is best understood in their context. The few examples discussed in this paper show how Specht interlaces American English with NP expressions to tell the stories of plural identities. In the specific case of Flannery, her transculturalism is manifest in her being a Nigerian on the one hand and retaining her American-ness on the other. Similarly, Kunle is willing to marry the American, to leave Nigeria for America and to accept Flannery's family as his. Kunle's readiness to be part of another culture signposts his understanding of the multifaceted nature of human existence.

\section{Conclusion}

Drawing examples from the author's reading of Specht's linguistic strategies vis-a-vis scholarly summations on the confluence of language and identity, the paper supports the view that people's use of language can help us to understand how they live in transculturation. We have seen how the novelist's use of loanwords, Nigerian English expressions and Nigerian Pidgin depict her characters' articulation of their multiple identities. In this way, Specht tries to show that literary language cannot be disconnected from the social uses to which it is put. Whether we admit it or not, we are always mindful of how we use language. Our use of language is in many respects constrained by what we want to say or the message we intend to communicate. This symbolic parallel provides us with examples of Flannery's simultaneous belonging to Nigeria and America. Belonging to Nigeria does not warrant abandoning her American-ness. The argument thus far is that an individual's choice of a language or languages is a contextual activity that determines both the linguistic form of a text and its implied meaning. 


\section{References}

Aboh, R. (2012). Lexical borrowing as a resource for the construction of identities in selected 21st-century Nigerian novels. Marang: Journal of Language and Literature, 22, 51-70.

Aboh, R., \& Uduk, H. (2016). The pragmatics of Nigerian English in Chimamanda Adichie's novels. Journal of Language and Education, 2(3), 1-13.

Adegbija, E. (1998). Lexico-semantic variations in Nigerian English. World Englishes, 8(2), 165-177.

Ahmed, K. (2016). Transnational migration, identity and the African literary experience. University of Uyo Journal of Humanities, 20(1), 133-152.

Ajtony, Z. (2013). Approaching literature with linguistic means: A few conclusions. Acta Universitatis Sapientiae, Philologica, 5(2), 255-263.

Allington, D., \& Swann, J. (2009). Researching literary reading as social practice. Language and Literature, 18(3), 247-264.

Amao, T. (2012). The use of Pidgin English as a medium of social discourse among Osun State University students. African Nebula, 5, 42-52.

Balogun, T. A. (2013). In defense of Nigerian pidgin. Journal of Languages and Culture, 4(5), 90-98.

Bitsani, E. (2016). Migration memory, cultural heritage: A vehicle of the intercultural identity of a city. The case study of the eastern Greek community and the Greek museums of Trieste Italy. Cogent Arts and Humanities, 3(1), 1-15.

Bradford, R. 1997. Stylistics. London: Routledge.

Cuccioletta, D. (2002). Multiculturalism or transculturalism: Towards a cosmopolitan citizenship. London Journal of Canadian Studies, 17, $1-11$.

Eka, D. (2002). Issues in Nigerian English usage. Uyo: Scholar Press.

Hobsbawm, E. (1996). Language, culture, and national identity. Social Research, 63, 1065-1080.

Hudson, R. (1996). Sociolinguistics. Cambridge, UK: Cambridge University Press.

Jowitt, D. (1991). Nigerian English usage. Lagos: Longman.

Kalpana, H. (2015). Reading identity and culture: Postcolonial perspectives in South Asian fiction. Gandhigram Literary Review, 4, 40-56.

Kehinde, A. (2010). Two of a kind: Thematic, ideological and aesthetic convergences in American and African literatures. In E. N. Kwofie \& B. Ayeleru (Eds.), Language and literature \& criticism. Essays in honour of Professor Aduke Adebayo (pp. 213-238). Ibadan: Zenith Bank House. 
Aboh, R./ Legon Journal of the Humanities 29.1 (2018)

Kavalski E. (2003). Notions of voluntary identity and citizenship in the Wonderful adventures of Mrs. Seacole in many lands. Jouvert: A Journal of Postcolonial Studies, 7(2), 1-12.

Lamidi, M.T. (2017). The syntax of multi-word expressions in Yorulish codemixing. Ghana Journal of Linguistics, 6 (2), 30-55.

Miall, D. S. (2002). Literary discourse. In M. A. Gernsbacher \& S. R. Goldman (Eds.), Hand book of discourse processes (pp. 321-355). Art Graesser, Mahwah, NJ: Lawrence Erlbaum Associates.

Maingueneau, D. (2010). Literature and discourse analysis. Acta Linguistica Hafniensi, 42, 147-158.

Odumuh, E. (1984). Educated Nigerian English as a model of standard Nigerian English. World Language English, 3, 231-235.

Onghena, Y. (2008). Transculturalism and relation identity. 181-184. Retrieved from http://www.iemed.org/publication/quaderns/10/q10_181pdf.

Park, J. S. (2012). Linguistic identities. In J. Mark \& A. Helmut (Eds.), The encyclopedia of global studies (pp. 1080-1084). Thousand Oaks, CA: Sage.

Porras, J.E. (2011). "Black Spanish' speech as ethnic identity in AfroColombian poetry: The case of Candelario Obeso. Journal of Pan African Studies, 4(5), 262-286.

Rahim, H. A. (2008). The evolution of Malaysian English: Influences from within. In S. A. Manan \& L. Sinha (Eds.), Exploring space: trends in literature, linguistics and translation (pp. 1-22). Newcastle: Cambridge Scholars Publishing.

Specht, M. H. (2015). Migratory animals. New York: Harper Perennial.

Tartaglia, J. (2016). Transculturalism and the meaning of life. Humanities, 5(2), $1-13$.

Tolliver, J. (1990). Discourse analysis and the interpretation of literary narrative. Style, 24(2), 266-283.

Tutuola, A. (1952). The palm wine drinkard. London: Faber and Faber.

Udofot, I. (2007). English and the Nigerian situation - Trends and perspectives. An inaugural lecture delivered at the University of Uyo, Nigeria, April 26, 2007.

van Dijk, T. (1985). Introduction. In T. van Dijk (Ed.), Discourse and literature: New approaches to the analysis of literary genres (pp. 1-13). Amsterdam: John Benjamins.

Verdonk, P. (2002). Stylistics. Oxford: Oxford University Press.

Widdowson, H. (2012). The pretext of interpretation. In O. DontchevaNavratilova \& R. Povolna (Eds.), Discourse interpretation: Approaches and applications (pp. 3-18). Cambridge, UK: Cambridge Scholars Publishing.

Yina, G. (2011). The semiotics of Tiv oral poetry. Makurdi: Aboki Publishers. 